\title{
Cultura no enfrentamento do agora
}

\section{[Culture in facing the now}

\section{Sergio Ricardo Retroz ${ }^{\mathrm{I}}$}

GARCÍA CANCLINI, Néstor. Política cultural: conceito, trajetória e reflexões. Organizadores: Renata Rocha e Juan Ignacio Brizuela (EDUFBA, 20I9).

RESUMO - O livro objeto desta resenha é constituído pela tradução de importantes textos de García Canclini sobre políticas culturais, com destaque para um publicado em I987. Conta ainda com uma coletânea de ensaios de especialistas brasileiros que comentam o pensamento do intelectual argentino. Propõe, dessa forma, uma reflexão sobre a influência de Canclini nas políticas culturais latinoamericanas, com especial atenção ao caso brasileiro. • PALAVRAS-CHAVE - Democracia; cultura; políticas culturais. - ABSTRACT - The book, the object of this review, consists of the translation of important texts by García Canclini on cultural policies, with emphasis on one published in 1987. It also has a collection of articles by Brazilian experts who comment on the thoughts of the Argentine intellectual. In this way, he proposes a reflection on Canclini's influence on Latin American cultural policies, with special attention to the Brazilian case. - KEYWORDS . Democracy; culture; cultural policies.

Recebido em 30 de junho de 2020

Aprovado em 27 de julho de 2020

RETROZ, Sergio Ricardo. Cultura no enfrentamento do agora. Revista do Instituto de Estudos Brasileiros, Brasil, n. 76, p. 266-273, ago. 2020.

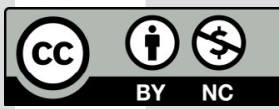

DOI: https://doi.org/Io.II606/issn.23I6-90IX.vIi76p266-273

I Universidade Federal do Estado do Rio de Janeiro (UniRio, Rio de Janeiro, RJ, Brasil). 
Foi em I987 que Néstor García Canclini publicou seu artigo intitulado "Políticas culturales y crisis de desarrollo" como introdução do livro Políticas culturales en América Latina, uma coletânea com artigos de outros estudiosos acerca das políticas culturais na América Latina, tendo no livro, inclusive, um texto assinado pelo brasileiro Sérgio Miceli. O artigo de Canclini passou a ser leitura obrigatória em estudos correlatos, mas nunca tinha sido traduzido para a língua portuguesa. Diante dos mais de 30 anos de sua publicação, Renata Rocha e Juan Ignacio Brizuela compuseram um livro não apenas com a tradução do referido artigo, mas também com a tradução de outros três textos de Canclini, sugeridos pelo próprio autor para atualizar seu pensamento - dois do início dos anos 2000 e um de 20I8. Os organizadores convidaram ainda renomados estudiosos brasileiros para relerem os textos de Canclini e tecerem seus comentários. O livro, que conservou como eixo central o artigo de I987, acabou por se tornar uma celebração da obra de Canclini acerca das políticas culturais, provocando uma reflexão coletiva sobre a influência do seu pensamento nos estudos e nas políticas de cultura na América Latina, com especial atenção ao caso brasileiro.

Antes de abordarmos propriamente o livro, especialmente nesses artigos que comentam a obra de Canclini, vale a pena recuperarmos o contexto no qual o autor argentino produziu seu artigo de I987. A importância desse artigo se deve, em grande parte, pela sua capacidade em sintetizar as discussões estabelecidas naqueles anos de grandes mutações nas políticas culturais. Na década de I980, emergia o conceito de democracia cultural, construído em confronto ao conceito de democratização da cultura, que vinha pautando a área desde a década de I960 na busca pela ampliação de público às chamadas artes eruditas. A democracia cultural, por sua vez, surgiu na compreensão de que cultura não se restringe a arte erudita, mas abarca as mais variadas expressões culturais geradas pelas coletividades. Uma política de democracia cultural residiria, neste sentido, na possibilidade de acesso da população aos meios de produção da cultura, dando espaço às suas expressões, dos mais diversos grupos sociais. De acordo com Isaura Botelho (200I, p. 8I-82), o conceito de democracia cultural estabeleceu "por princípio favorecer a expressão de subculturas particulares e fornecer aos excluídos da cultura tradicional os meios de desenvolvimento para eles mesmos se cultivarem, segundo suas próprias necessidades e exigências". 
No seu artigo, Canclini, atento a esse debate, chega a uma definição de políticas culturais nos seguintes termos: "o conjunto de intervenções realizadas pelo Estado, pelas instituições civis e pelos grupos comunitários organizados a fim de orientar o desenvolvimento simbólico, satisfazer as necessidades culturais da população e obter consenso para um tipo de ordem ou de transformação social” (p. 56).

No nosso entendimento, o conceito de democracia cultural, trabalhado por Canclini, tem muita semelhança com o conceito de cidadania cultural cunhado por Marilena Chauí. Assim como Canclini, Chauí (I995) também elabora uma tipologia para classificar os modos de gestão da cultura, em certa medida coincidente com a tipologia desenhada pelo autor argentino. Chauí entende a cultura como direito de todos os cidadãos e defende a democratização dos seus meios de produção, bem como aponta para uma nova cultura política. Trata-se de um conceito em diálogo e consonância com aquele de Canclini, conceito que não se limitou ao pensamento, mas pautou a atividade da brasileira como secretária da Cultura na cidade de São Paulo, entre I989 e I992, durante uma das primeiras gestões municipais do Partido dos Trabalhadores (PT). A gerência de Chauí na secretaria paulistana serviu de referência para outras experiências do PT, tanto em gestões municipais e estaduais, como também no governo federal, principalmente na gestão do ministro Gilberto Gil, não coincidentemente tratado em alguns dos textos publicados no livro objeto desta resenha. Ou seja, muito das ideias de Canclini, de certa forma, permeou experiências brasileiras de gestão pública da cultura.

Recuperar os conceitos de políticas culturais formulados nos anos I980 é voltar-se para um pensamento germinado em um contexto de significativas transformações na sociedade, na política e na economia. Na América Latina, o encerramento das ditaduras era recente e se estruturavam os fundamentos para a consolidação das democracias, o que ocorria em plena crise econômica e inflacionária. A política cultural era entendida por alguns intelectuais da época, entre eles Canclini, como parte fundamental nesse processo de estruturação da democracia e de viabilidade do desenvolvimento econômico e social, por ser a cultura dotada de poder criativo, diante de um momento em que se vivenciava o esgotamento do modelo econômico vigente. Canclini, ao lado de outros, falava em "crise de desenvolvimento", visível nas contradições sociais, na explosão demográfica e na crise ecológica. Para o intelectual argentino, a dita "crise de desenvolvimento" não poderia ser superada com soluções meramente econômicas e políticas, sendo necessário questionar "as bases culturais da produção e do poder" (p. 53). O pensamento de Canclini e de outros intelectuais do período era, então, atravessado pela questão do desenvolvimento das sociedades e de reavaliação do modelo desse desenvolvimento. A própria Organização das Nações Unidas para a Educação, a Ciência e a Cultura (Unesco) vinha defendendo a inserção das questões da cultura na pauta dos programas de desenvolvimento das nações, com o argumento de que o avanço de uma nação não poderia ser medido apenas pelo sucesso de sua economia. Nesse bojo, alguns intelectuais brasileiros tanto acompanharam as discussões da Unesco, como também contribuíram nas suas formulações, atuando no órgão internacional. Entre eles, citamos Aloísio Magalhães (I985, p. 48-49), defensor combativo dos "bens culturais" enquanto "instrumento para um desenvolvimento harmonioso", e Celso Furtado (20I2), segundo o qual o 
desenvolvimento cultural poderia também promover as bases para a introdução de mudanças estruturais no sistema econômico.

A retomada do texto de Canclini, marco nessas discussões, nos coloca, então, diante de um debate acerca de soluções para uma crise econômica e política, num momento de estruturação das bases democráticas e de efervescência dos movimentos sociais, desejosos de espaços para sua participação política. Um período em que emergiam questões e problemas que dialogam com a atualidade, seja no Brasil, na América Latina, ou no mundo, o problema da conjugação cultura, democracia e modelo de desenvolvimento econômico. E são essas questões, do nosso atual contexto político, econômico e cultural, que fermentam os textos produzidos para comentar a obra de Canclini. Todos os autores do livro buscam verificar a atualidade do seu pensamento e costurar relações com a realidade brasileira, sendo este o fio condutor priorizado aqui na leitura dos diversos textos que compõem a publicação.

Logo no prefácio, Leonardo Costa aponta para a importância de Canclini na reflexão e definição de políticas culturais, posicionadas a favor de intervenções capazes de reunir diversos autores sociais e promover mudanças por meio da cultura. Leonardo Costa vê ainda como atual a observação de Canclini do pouco interesse do Estado e dos partidos políticos pelo campo da cultura. Costa percebe essa atualidade ao verificar nos planos de governo dos candidatos à presidência do Brasil, em 20I8, a quase ausência de propostas de políticas públicas para a cultura; haja vista que o candidato eleito simplesmente ignora o tema em seu plano de governo.

Os organizadores do livro, Renata Rocha e Juan Ignacio Brizuela, no texto de apresentação, consideram o conceito de políticas culturais de Canclini paradigmático e atual por três motivos: por evidenciar que a política cultural não é definida apenas pelo Estado, mas por múltiplos agentes e instituições; por reafirmar a cultura enquanto necessidade, sendo as demandas da sociedade cruciais para pautar as políticas; e, por fim, por reconhecer a dimensão simbólica do desenvolvimento, bem como o papel da cultura na orientação de tal desenvolvimento. Os organizadores, ao comentar os dois textos de Canclini datados do início dos anos 2000, os entendem como atualização das definições do autor, não mais restrita ao contexto dos estados nacionais, mas atenta também ao contexto do mundo globalizado, fundamental para compreensão do lugar das culturas e das identidades na contemporaneidade.

Ao adentrarmos nos textos encomendados para o livro, encontramos "Políticas culturais em Néstor García Canclini: algumas observações”, de José Roberto Severino, segundo o qual a atualidade da obra de Canclini está, entre outros motivos, no fato de seu trabalho estabelecer novos marcos conceituais para as políticas culturais, agora sob a égide da democracia e da diversidade cultural. Na visão de Severino, em Canclini, as políticas culturais estão sempre ligadas a uma questão de aprofundamento da democracia, sendo que suas proposições colocariam no horizonte o tipo de sociedade que se deseja construir. Por isso, Canclini buscaria fugir do ordenamento burocrático, levando em consideração os estratos sociais e sua conflituosa relação, permeada pelo mercado. Canclini, na visão de Severino, propõe uma política cultural capaz de perceber os diversos atores, meios e possibilidades de realização, a fim de dar espaço à pluralidade e à criação de novas metáforas na imaginação social, de onde seria possível pensar de forma criativa inovações para 
a vida social. Nesse sentido, a política cultural pensada por Canclini contribuiria ao ordenamento social, não apenas em sua manutenção, mas em sua capacidade de reelaboração e transformação.

Lia Calabre, por sua vez, em "Sobre o conceito de políticas culturais", percebe a atualidade do conceito de Canclini na proposta de que as políticas culturais sejam construídas conjuntamente entre o Estado e a sociedade civil, com especial participação dos grupos comunitários e organizados. A obra, segundo a autora, é ainda atual por entender a cultura como direito de todos - não apenas no acesso, mas na possibilidade de atuar sobre os meios de produção - e por colocar o Estado como garantidor desse direito. Calabre atenta, ainda, aos perigos do uso descontextualizado do conceito de política cultural de Canclini, uma vez que atender às demandas da sociedade e fomentar a participação nas decisões de poder podem ser iniciativas pautadas por uma cultura hegemônica, constantemente reforçada pelos grandes conglomerados dos meios de comunicação, pela indústria cultural. Nesse sentido, seria preciso contextualizar o conceito de Canclini, concebido num posicionamento em defesa das múltiplas identidades. O desafio de colocar em prática o conceito de política cultural de Canclini estaria, então, na garantia da autonomia cultural dos sujeitos sem provocar a mera reprodução de discursos hegemônicos, de forma a ter por meta o fortalecimento da diversidade de identidades e culturas. Lia Calabre vê ainda, no caso brasileiro, avanços e recuos na implementação desse conceito de Canclini, alinhado com as discussões propagadas pela Unesco. Se a Constituição de I988 pode parecer um avanço para a área cultural, o governo federal ao longo dos anos I990 provocou grandes recuos; se os anos 2000 podem ter sido o início de uma implementação daqueles conceitos na esfera federal, a atual crise democrática representativa estabelecida no país impõe novos recuos.

Em "A atualidade das intervenções de Néstor García Canclini”, Isaura Botelho evidencia alguns exemplos específicos de gestão cultural no Brasil, que conversam com os pressupostos generalistas apontados por Canclini. Entre os exemplos, se sobressai o caso brasileiro do Ministério da Cultura (MinC), entre 2003 e 20II, especialmente no período do ministro Gilberto Gil. Segundo a autora, foi nessa experiência que se estabeleceram as estruturas basilares para a implementação de uma democracia cultural no país, quando se partiu de uma dimensão antropológica da cultura, capaz de superar a dicotomia entre cultura popular e cultura erudita, numa busca pelo fortalecimento de iniciativas culturais de grupos espontâneos, de naturezas diversas. A estruturação da área da cultura, concebida naquele governo, na visão da autora, teria visado dar uma contribuição ao desenvolvimento social, econômico e simbólico, ao priorizar o incentivo de movimentos culturais já existentes e fomentar um ambiente de discussão pública sobre as políticas a serem implementadas. Apesar dos avanços, Botelho fala dos retrocessos na área da cultura ocorridos após o impedimento da presidenta Dilma Rousseff, lembra ainda a tentativa de decretar o fim do MinC, durante o governo Michel Temer, evitado naquele momento por mobilização social, mas efetivado no início do atual governo. Por essas descontinuidades, Botelho vê a democracia cultural de Canclini como um paradigma ainda a ser buscado no Brasil.

No ensaio "Política cultural, movimentos sociais e democracia: releitura de 
questões a partir de ‘Políticas culturales y crisis de desarrollo’”, Alexandre Barbalho foca sua reflexão na relação entre política cultural, movimentos sociais e democracia. De acordo com ele, Canclini estava atento ao potencial cultural dos movimentos sociais na construção de um ambiente democrático, num momento em que a América Latina buscava deixar para trás suas experiências autoritárias. Por isso, Canclini falaria em democracia cultural e em democracia participativa enquanto política de acesso aos bens culturais. Foi dos movimentos sociais, segundo Barbalho, que partiram o questionamento à cultura hegemônica e a exigência de transparência e participação na política, a ponto dessa exigência se impor para os governos dos anos I980 e I990. Todavia, o que se viu, como no caso brasileiro, foram governos que concomitantemente à implementação de instrumentos de governança, tenderam à diminuição do poder público e maior abertura ao setor privado. Barbalho percebe ainda que essa hegemonia neoliberal e conservadora continuou a ser questionada por movimentos sociais latino-americanos apoiados na formulação de outras bases político-culturais, sendo exemplo disso o Movimento dos Trabalhadores Sem Terra (MST), no Brasil, que tem a cultura como pilar de sustentação de sua luta social. O autor também cita o Ministério da Cultura, nos governos Lula e Dilma, como exemplo brasileiro de implementação de políticas culturais diversas, conectadas com a cultura forjada nos movimentos sociais. No Brasil, como em outros países da América Latina, na atualidade, se vive um movimento de negação dessas experiências, numa retomada dos ideais neoliberais e do pensamento conservador, o que faz Barbalho acreditar na urgência de se reavivar a confluência entre movimentos sociais e cultura, sendo que apenas na participação dos movimentos socioculturais nos processos políticos é que será possível apontar para uma nova cultura política, negadora do autoritarismo e alternativa ao modelo neoliberal. Nesse sentido, a confluência entre cultura, movimentos sociais e democracia presente no pensamento de Canclini ainda se mostra como atual e desafiadora.

Humberto Cunha Filho, em "Políticas culturais em Canclini em contraste com a Constituição cultural do Brasil”, decupa a definição de políticas culturais cunhada por Canclini em seu texto de I987 e compara tal definição com aquela desenhada no texto constitucional brasileiro de I988. Para Cunha Filho, tanto o texto de Canclini como a Constituição de I988 são resultados de uma trajetória daquelas últimas três décadas, nas quais se deu uma construção teórica a respeito das políticas culturais. Para ele, Canclini melhor modula seu pensamento ao longo dos anos seguintes, na medida em que sua definição pauta políticas culturais implementadas nas nações latino-americanas.

O livro é encerrado com um texto recente de Canclini, adaptado para a nova publicação, texto que reforça e atualiza as ideias do autor. Trata-se de uma reflexão sobre o posicionamento do México frente aos desafios contemporâneos impostos às suas políticas culturais, com considerações que servem a outros países latino-americanos. No texto, Canclini defende a necessidade de o Estado atentar para as mudanças socioculturais em curso para uma reavaliação de suas instituições, a fim de superar sua "inércia burocrática" e desenvolver alternativas frente o avanço do monopólio de grandes corporações de comunicação. Segundo o autor, no atual contexto, não se trata de proteger a cultura de dentro de suas fronteiras, mas de saber inseri-la no mundo. 
Canclini vê como necessário o apoio estatal a uma cena cultural independente, pulsante nas sociedades de maneira intermitente, cena esta normalmente marcada pela precariedade de recursos e dificuldade para sua própria manutenção. Mas esse apoio estatal, para ser eficiente, deve levar em conta as mudanças em curso e, como exemplo, o autor trata de três "mutações", a do cinema, da leitura e das práticas digitais, mutações provocadas pelo acesso à internet, pelo modo como os jovens lidam indistintamente com os diversos suportes da informação e como atuam politicamente por meio de redes sociais. A internet, que aparentemente amplia o campo de exercício da cidadania, permitindo, por exemplo, petições que normalmente se perderiam na burocracia dos Estados, demonstra seu potencial justamente contrário, quando comportamentos e desejos são transformados em algoritmos a serviço do marketing e da condução dos rumos da política. Nesse contexto, como constata o autor, não é de admirar que o Facebook, "maior ilusionista da participação de todos", seja um "monopólio global" (p. I50). Canclini chama de "políticas desglobalizantes" aquelas implementadas pelo presidente dos EUA, pelo Brexit e pelas "forças xenófobas", por serem negadoras da globalização, na medida em que cerceiam, por exemplo, a locomoção de contingentes populacionais pelo mundo. Essas políticas seriam uma resposta equivocada ao problema social no qual nos instalamos, em que as pessoas não se sentem representadas, nem veem soluções para seus problemas ensaiadas pelos Estados. De acordo com Canclini, na atualidade emerge um desafio colocado a todas as épocas, a de propor uma educação adequada ao nosso tempo, uma que, no seu entendimento, não estaria na mera transmissão de patrimônios, mas no uso criativo deles enquanto repertório para a colocação de soluções para o presente.

A democracia cultural de Canclini, enfim, tem muito a nos dizer nos dias de hoje, quando o Brasil, ao lado de tantos outros países, sofre o peso de políticas conservadoras e, concomitantemente, o mundo passa por uma pandemia que nos impõe questionamentos a respeito do modelo vigente de produção econômica, causa de desigualdades globais e da vulnerabilidade social de grande parte das populações mundiais. Falar em cultura, no atual contexto, é falar na possibilidade de renovação do sistema simbólico e na constituição de novos parâmetros à emergência igualmente nova de soluções aos problemas contemporâneos. Talvez por isso, num contexto de incertezas e de aguçamento dos conflitos sociais, determinados grupos sociais remetem críticas às políticas culturais e buscam fragilizá-las, numa tentativa de manutenção do estabelecido e de impedimento da criação de novas propostas de organização social. A leitura de Canclini e desse conjunto de autores debatedores de sua obra nos leva a pensar o papel da cultura na contemporaneidade, bem como a pensar em estratégias na superação dos problemas sociais, políticos e econômicos que nos afligem. 
SERGIO RICARDO RETROZ é doutorando no Programa de Pós-Graduação em Museologia e Patrimônio da Universidade Federal do Estado do Rio de Janeiro (UniRio) e do Museu de Astronomia e Ciências Afins (MAST). Sua pesquisa conta com financiamento da Coordenação de Aperfeiçoamento de Pessoal de Nível Superior (Capes). sretroz@yahoo.com.br https://orcid.org/o0oo-0002-2933-0260

\section{REFERÊNCIAS}

BOTELHO, Isaura. Dimensões da cultura e políticas públicas. São Paulo em Perspectiva. São Paulo, v. I5, n. 2, 200I, p. 73-83.

GARCÍA CANCLINI, Néstor (Ed.). Políticas culturales en América Latina. México, D.F:: Editorial Grijalbo, I987. CHAUÍ, Marilena. Cultura política e política cultural. Estudos Avançados, v. 9, n. 23, I995, p. 7I-84.

FURTADO, Celso. Ensaios sobre cultura e o Ministério da Cultura. Rio de Janeiro: Contraponto, Centro Internacional Celso Furtado, 2012.

MAGALHÃES, Aloísio. E triunfo?: a questão dos bens culturais no Brasil. Rio de Janeiro: Nova Fronteira; Brasília: Fundação Nacional Pró-Memória, I985.

MICELI, Sérgio. Estado, mercado y necesidades populares: las políticas culturales en Brasil. In: CANCLINI, Néstor (Ed.). Políticas culturales en América Latina. México, D.F.: Editorial Grijalbo, I987, p. I27-I44. 